\title{
"O porco fala inglês?!": \\ a construção da percepção e do conceito de línguas por crianças da educação infantil
}

\author{
Barbra R. Sabota \\ Universidade Estadual de Goiás \\ barbrasabota@gmail.com \\ Claudia R. V. Bertoso Leite \\ Universidade Estadual de Goiás \\ claudiabertoso@gmail.com
}

\section{Resumo}

Este estudo tem por objetivo descrever e analisar a percepção e a formação do conceito de língua estrangeira que crianças de 4 anos de idade de um Centro Municipal de Educação Infantil construíram ao assistir a um programa de televisão em espanhol. A pesquisa foi desenvolvida segundo parâmetros qualitativos de coleta e análise de dados com observação participativa. Sobpremissas da teoria sociocultural foi desenvolvida uma sequência gradativa de ações mediadas por scaffolding. Nossa análise permite inferir que a construção do conhecimento da e sobre a LE das crianças é viável quando considera os conhecimentos prévios das crianças e as contribuições do grupo para a construção de conceitos.

Palavras-chave: Criança. Língua estrangeira. Mediação.

\begin{abstract}
This study aims to describe and analyze the perception and construction the concept of a foreign language by four-year-old children in a public daycare in the city of Uruaçu, in the countryside of Goiás, Brazil, as they are exposed to a TV show in Spanish for the first time. The research was conducted according to qualitative parameters of data collection and analysis, being considered a participant observation. Under the assumptions of the sociocultural theory, a gradual sequence of actions mediated by scaffolding was developed. Our analysis allows us to infer that the construction of knowledge of and about this foreign language by children is feasible when
\end{abstract}


considering their previous knowledge and the group contributions for the construction of the concepts.

Keywords: Child. Foreign language. Mediation.

\section{Introdução}

Pensar nos desafios da prática docente na sociedade do conhecimento, sobretudo na educação infantil, requer um envolvimento em alternativas que informem e permitam a construção de conhecimentos de modo interessante e atraente. No contexto atual, em que as tecnologias estão presentes e mudando o jeito de brincar, educar e cuidar das crianças, é interessante abrir um diálogo a fim de aproveitarem-se as interações sociais permitidas por aquelas no que parece ser oportunidade de aprendizagem a partir delas.

O intuito desta pesquisa é explorar a televisão, que, apesar de não ser nova,configura-se como um recurso tecnológico bem presente nos lares e nos Centros de Educação Infantil. Considera-se que a utilização dos recursos tecnológicos podepropiciara interação entre as crianças e adentrar o reconhecimento de outras formas de comunicação, línguas e culturas, se usados como elemento mediador, auxiliando na construção de conhecimentos necessários ou para a resolução de problemas específicos (BRAGA, 2013).

A pretensão da inferência desta pesquisa com crianças pequenas intenciona corroborar o modo como a criança pode, convivendo em sociedade, construir sua própria identidade de falante nativo, fazer-se e constituir-se distinto de outros grupos que se comunicam em outra língua, ativando desde cedo uma consciência linguística.

A intenção específica deste estudo é,portanto,descrever e analisar a percepção de língua estrangeira (doravante LE) de crianças de 4 anos de idade e observar como elas constroem o conceito de línguas. Nosso foco é o momento que antecede a aprendizagem formal de outra língua, o instante de um primeiro contato com a LE, neste caso, o espanhol, e a tomada de consciência da existência de línguas diferentes da sua. 


\section{Aspectos metodológicos}

Esta é uma pesquisa qualitativa cuja essência, segundo Minayo (1995), define as representações sociais como categorias de pensamento que expressam a realidade e a explicam, ao mesmo tempo em que a justificam e/ou a questionam. Utilizou-se como recurso a observação participante, ou seja, registra-se, além da observação direta da situação em estudo, o envolvimento do pesquisador em toda a metodologia exigida na situação em análise (LÜDKE; ANDRÉ, 2013).

$\mathrm{O}$ estudo foi realizado, após assinatura do Termo de Consentimento pela Secretaria Municipal de Educação e pela direção da instituição educativa, em uma turma de 26 crianças com idade de 4 anos que frequentam o agrupamento denominadoJardim I de um Centro Municipal de Educação Infantil (CMEI) ${ }^{1}$ da cidade de Uruaçu, interior do Estado de Goiás.

Conforme análise da Proposta Político Pedagógica da instituição, as crianças do CMEI são agrupadas por idade, e cada agrupamento tem uma parte da rotina diária comum à instituição (horários da entrada e saída, lanches, refeições e higienização) e uma rotina deatividadesespecíficasde cada agrupamento, com horários estabelecidos conforme oplanejamento do professor (rodas de conversa, hora da história, brincadeiras, atividades de leitura e escrita). Na Proposta Pedagógica, o conteúdo curricular deve ser tratado de modo interdisciplinar e abranger temas como matemática, linguagem

\footnotetext{
${ }^{1}$ Em 1996, quando a nova Lei de Diretrizes e Bases da Educação (LDB) entrou em vigor, o sistema educativo foi remodelado, passando a compreender dois níveis: Educação Básica (composta por três etapas: Educação Infantil, Ensino Fundamental e Ensino Médio) e Ensino Superior. Na Educação Infantil, nosso foco neste estudo, as crianças são relocadas em creches (para as crianças de 0 a 3 anos) e em pré-escolas (para crianças de 4 a 5 anos). A instituição onde ocorreu o estudo comporta as duas etapas da Educação Infantil (tanto creche como pré-escola), sendo designada por Centro Municipal de Educação Infantil, comumente chamado de CMEI.

2 À ocasião também foram coletados dados para a pesquisa de mestrado desenvolvida por Bertoso Leite intitulada "A presença da televisão na Educação Infantil".
}

Horizontes de Linguística Aplicada, ano 12, n. 2, 2013 
oral e escrita, música, artes, natureza e sociedade e corpo e movimento. De toda forma, pôde ser percebido que nenhum conteúdo de língua estrangeira integra o quadro como proposta de currículo.

Como o objetivo central deste estudo é o desenvolvimento da consciência linguística com base na percepção de língua estrangeira e da diferenciação minha língua - língua do outro, optou-se por apresentar às crianças o espanhol. Considerou-se a hipótese de que a semelhança entre os idiomas português e espanhol, ambos de origem latina, poderia ser um fator que despertaria a curiosidade das crianças sobre o que acontecia com a amostra de língua a ser introduzida.

Nas ações da pesquisa, a inserção da LE se dá em conjunto com a língua materna (LM). Considera-se que o uso da LM pode ser um importante mediador na aquisição de uma outra língua, como afirma Melo (2004), uma vez que o conhecimento que dispomos de nossa língua passa a integrar a base de nosso conhecimento sistêmico (o que sabemos sobre a língua) e de nossas estruturas cognitivas, o que favorece a integração de novos conhecimentos a essa base, auxiliando na compreensão de novas informações. Essa posição pode auxiliar tanto na aprendizagem da LE como na expansão do conhecimento que se tem da própria LM (MELO, 2004; FRANÇOIS, 2006).

$\mathrm{O}$ insumo linguístico selecionado foi um episódio do programa infanto-juvenil Chaves, ${ }^{3}$ por ter sido apontado em entrevista exploratória, etapa preparatória da pesquisa e"fundamental para uma definição mais precisa do objetivo de estudo" (LÜDKE; ANDRÉ, 2013, p.25) como o favorito das crianças do agrupamento escolhido.O episódio por nós utilizado na pesquisa foi "O aniversário do Kiko",que foi gravado e levado para o grupo em duas versões: em seu original, em espanhol, e dublado, em português. ${ }^{4}$

\footnotetext{
3“Chaves" é um dos mais populares seriados infantis da televisão brasileira. De origem mexicana, o seriado, produzido entre 1973 e 1983, é reprisado ainda hoje e mantém o recorde de audiência e de permanência da televisão (pelo SBT).Adaptado de <http://www.mentemoderna.com.br/personagens-doseriado-chaves-ontem-e-hoje.html>. Acesso em: 23/02/2013.

${ }^{4}$ Devidoà extensão do artigo, a análise da exibição da versão do vídeo em português e da exibição do vídeo da dublagem do programa será relatada em outro texto.
} 
O episódio retrata a preparação de uma festinha para o aniversário de Kiko, em sua casa. Ele convida todos os amigos, que durante a festa discutem por causa das brincadeiras que deveriam ser feitas. No final do episódio, o bolo de aniversário é destruído por Chaves, mas todos aprendem a compartilhar suas coisas. O episódio foi apresentadopara as criançasinicialmente em espanhol. Posteriormente, seguimos mediando o visionamento do vídeo e alternando línguas (português-espanhol), e, por fimm, concluímos com a versão em espanhol novamente, tal como descrito em maiores detalhes na análise dos dados.

\section{Premissas teóricas}

Nota-se uma crença recorrente na ideia predominante de que seja muito fácil para as crianças aprenderem uma nova língua, como sugere a teoria do período crítico. ${ }^{5}$ Entretanto, como vemos em Figueiredo (1995), a idade do indivíduo é apenas um dos fatores que influenciam o modo como se aprende uma língua estrangeira. Existem vários outros fatores definidores, como diferenças individuais, aspectos linguísticos (como a proximidade entre as línguas), oportunidades para aprendizagem e motivação.

François (2006), ao estudar a relação entre a criança e a língua, afirma que os pequenos mergulham na linguagem sem estabelecer uma relação unívoca com uma realidade que seria a língua. A criança consegue refazer, durante o processo de aprendizagem de uma língua, o "trabalho de relacionar aquilo que chega a ela por caminhos diferentes: o campo da percepção, da ação, do sentido, do poder e da impotência e o campo das palavras" (FRANÇOIS, 2006, p. 187), ou seja, ela recebe e percebe a língua, detectando atentamente os pontos de contato entre línguas, porém sem uma distinção clara de idiomas diversos.

\footnotetext{
${ }^{5}$ A teoria do "período crítico" refere-se à crença de que indivíduos mais jovens teriam melhores chances de ser bem-sucedidos na aquisição de uma LE, considerando-seque os indivíduos teriam sua estrutura biológica constituída e planejadapara adquirir uma língua antes da puberdade, remetendo à plasticidade dos órgãos vocais.
}

Horizontes de Linguística Aplicada, ano 12, n. 2, 2013 
Rocha (2007), que pesquisa a aprendizagem de LE por crianças por uma perspectiva intercultural, afirma que é preciso "auxiliar a criança a construir um caminho que a ajude a ampliar o conhecimento de si própria e do mundo em que vive, fortalecendo-a com uma visão positiva e crítica das diferenças, e integrá-la no mundo globalizado" (ROCHA, 2007, p. 283). A autora propõe o fortalecimento da identidade da criança pela participação efetiva em uma sociedade plurilíngue e pluricultural, como a que está inserida.

Fica evidente a preocupação da autora (ROCHA, 2007) com a relevância do contexto sócio-histórico para o desenvolvimento cognitivo da criança, que se dá mediado pela linguagem e pelo processo de formação de conceitos. Para Vygotsky (1991), o processo de formação de conceito é central para o desenvolvimento do homem como ser social e culturalmente formado. O autor explica que, tal como os outros processos superiores, o processo de formação de conceitos é mediado por signos, que neste caso é a palavra.

A formação de conceitos é o resultado de uma atividade complexa, em que todas as funções intelectuais básicas tomam parte. No entanto, o processo não pode ser reduzido à associação, à atenção, à formaçãode imagens, à inferência ou às tendências determinantes. Todas são indispensáveis, porém insuficientes sem o uso do signo, ou palavra, como o meio pelo qual conduzimos as nossas operações mentais, controlamos o seu curso $e$ as canalizamos em direção à solução do problema que enfrentamos (VYGOTSKY, 1991, p. 73, grifo nosso).

Nesse trecho fica evidente que para o autor da teoria sociocultural a formação de conceitos é um processo que envolve diversas habilidades, destacadas em itálico, e que elas atuam em conjunto para fomentar o desenvolvimento do indivíduo, que ocorre ao longo da vida.

É central neste estudo o entendimento de como os conhecimentos prévios ou conceitos espontâneos (VYGOTSKY, 1991) que as crianças trazem sobre o conhecimento da existência de língua estrangeira são fundamentais na distinção entre as línguas e na construção do conceito de língua. As crianças entram na linguagem por 
modos diversos (relacionando ações e fala, observando objetos serem nomeados, associando às sensações, entre outros), sempre envolvidos em um contexto, que as auxiliam a entender o sentido das palavras, a formar conceitos, daí a dificuldade inicial de formar conceitos sobre língua (FRANÇOIS, 2006), o que lhes é abstrato por demais.

Buscamos neste estudo investigar como ossuportes ou apoios apresentados às crianças pelo professor mediador podem contribuir para a criação de um contexto propício para a formação do conceito de língua (materna $x$ estrangeira) e que os processos envolvem esta descoberta para elas. Partimos da premissa de que este pode ser um fator facilitador para o desenvolvimento da aprendizagem de línguas pela criança, pois o contato com o diferente (espanhol, no caso deste estudo) gera um problema e leva ao desencadeamento de habilidades como a atenção, a análise e a inferênciana formação do conceito "língua".

Nessa medida, aguçando a curiosidade da criança, pode-se acrescentar, gradativamente, sistematicidade e reflexividade, base para caminhar na efetivação de conceitos científicos, nocaso, a construção do entendimento de que existem outras línguas. Sobre isso, o autor desta teoria afirma:

Pode-se remontar a origem de um conceito espontâneo a um confronto com uma situação concreta, ao passo que um conceito científico envolve, desde o início, uma atitude "mediada"em relação ao seu objeto. [...] É preciso que o desenvolvimento de um conceito espontâneo tenha alcançado um certo nível para que a criança possa absorver um conceito científico correlato(VYGOTSKY, 1991, p.93).

Resumidamente, a elaboração de conceitos pelas crianças, segundo Vygotsky (1991), só emerge quando passa a fazer parte do seu cotidiano. Nessa direção, o processo de aprendizado do conceito línguas exigirá como premissa a mediação do outro, nesse caso, do professor, para que as crianças da pré-escola internalizem e se apropriem dos conceitos "a minha língua e a língua de outros povos", para assim utilizá-los quando necessário.

A interação mediadora permite esse entendimento sem depender de demarcação biológica, como, por exemplo, idade ou sexo, Horizontes de Linguística Aplicada, ano 12, n. 2, 2013 
especialmente quando há situações de colaboração nas quais os discursos são construídos durante a interação. Na perspectiva sociocultural, é por meio da negociação de sentido que a criança adquire a língua como um construto social, sempre em decorrência de uma operação intermental que se torna intramental.

Os conceitos científicos, entretanto, exigem em sua elaboração a utilização de operações lógicas complexas, o que pode ainda não ser dominado pelas crianças pequenas (como as de nossa pesquisa). No entanto, na perspectiva vygotskyana, "o aprendizado de novos conceitos e palavras pela criança é questão de oportunidade" (VYGOTSKY,1991, p. 72), e ainda "antecipamos uma ampliação do estudo do desenvolvimento e do aprendizado para as faixas etárias mais baixas. Afinal de contas, o aprendizado não se inicia na escola" (VYGOTSKY,1991, p. 100). Para o autor, a aprendizagem de novos conceitos deve, sim, passar por situações diversificadas, interessantes e significativas, de sorte que o processo de elaboração conceitual parta imprescindivelmente dos conceitos cotidianos, concretos, ou seja, das questões vivenciais.

Ao inserir a LE na infância oportuniza-se o desenvolvimento da competência intercultural, permitindo que as crianças conheçam outras culturas e aprendam a ter respeito por elas (FERNANDEZ; RINALDI, 2009, p. 357). Para as autoras,

[...] permitir que o primeiro contato com línguas estrangeiras aconteça naturalmente, ainda que num espaço de aprendizagem formal, através de jogos e brincadeiras, maneira frequente pela qual as crianças aprendem, pode contribuir para se criar uma base sólida de comportamento $e$ de desenvolvimento tanto de conhecimento de outros idiomas quanto de tolerância em relação ao diferente.

Além disso, o fato de aprender (ou de serem apresentadas ao) espanhol como LE pode ser significativo por algumas razões, dentre elas o fato de esta ser a língua oficial da maioria dos países vizinhos ao Brasil, conhecê-la pode ampliar oportunidades de contato (pessoal, cultural, artístico, etc.), e pela proximidade com o português, o quepode favorecer a reflexão metalinguística sobre nossa LM. 
Neste estudo, a atuação pedagógica do professor se dá pela interação mediadora, o que ocorre por meio da estratégia de scaffolding (andaime, em português, também traduzido em alguns textos acadêmicos como suporte mediado). Essa estratégia consiste no auxílio fornecido pelos pares (tanto pelo professor como pelas próprias crianças do grupo) na realização de uma tarefa (WOOD; BRUNER; ROSS, 1976; VILLAMIL; GUERRERO, 1996). À medida que a construção avança, a mediação diminui, ou seja, os andaimes são retirados, deixando a construção mais autônoma e livre. Sobre a importância dessa estratégia de mediação pedagógica, Paniagua e Palacios (2007, p. 57) destacam ser necessária a aplicação, pelo adulto interagente, de certa "intencionalidade educativa, que organize o ambiente e ordene as experiências", cuidando para que gradativamente as ações e as aquisições se tornem cada vez mais independentes. Rocha (2007) corrobora a validade dos scaffoldingsna interação com crianças fornecidos pelasatividades de jogos, música, brincadeiras, além de trabalho por temas por estabelecerem contextos de "uso situado da linguagem" (ROCHA, 2007, p. 307).

\subsection{A televisão como recurso pedagógico na educação infantil}

A televisão é um recurso tecnológico já normalizado, ou seja, seu uso já integra o cotidiano das pessoas sem causar estranhamento, sendo em geral utilizado com fins pedagógicos para a visualização de vídeos (OLIVEIRA, 2013) e posterior discussão. Considerada uma tecnologia interativa, a TV permite a renovação da relação do usuário com a imagem e com o conhecimento, embora muitos educadores rejeitem seu uso como um recurso capaz de potenciar a construção do conhecimento (SILVA, 2007). Para Guareschi e Biz (2005), a linguagem televisiva possui dois recursos no seu estilo que, combinados ao movimento, atraem sobremaneira os sentidos humanos: o som e a imagem, e, nesse sentido, pode-se reforçar a validade desses efeitos para as crianças.

Em pesquisa, Guareschi e Biz (2005) relatam que o brasileiro fica em média 3,9 horas diárias diante da TV. Ressalte-se que em algumas vilas periféricas as crianças assistem à TV durante seis a nove 
horas diárias, como, por exemplo, principalmente aquelas cujos pais têm medo de deixá-las na rua.

Com base na pesquisa de Guareschi e Biz (2005), na qual está dito que as crianças assistem a uma média de quatro horas diárias de programação, pode-se inferir que quando adentram a pré-escola as crianças já possuem mais de seis mil horas como espectadores, o que lhes propicia conhecimento sobre vários gêneros televisivos. Isso lhes permite o acesso a dois tipos de conhecimento importantes para o processo de aquisição da linguagem: sobre gêneros discursivos,uma vez que programas televisivos (seriados, desenhos, noticiários)retratam a narração (e processos de construção) e a descrição;além de auxiliálas na ampliação do conhecimento (e compreensão) de mundo antes de chegarem à instituição de Educação Infantil.

Rodrigues (2003) discute as peculiaridades da criança da Educação Infantil e desenvolve uma proposta de usos da televisão e do vídeo para esse público. Sua proposta utiliza as potencialidades que os programas podem oferecer à prática educativa do professor e à aprendizagem da criança. Partindo da premissa de que as noções de espaço e de tempo das crianças estão sendo construídas justamente durante o tempo da Educação Infantil, ela defende uma proposta educativa que visa "promover a criatividade e a criticidade, respeitando a criança e contribuindo para a formação de sua cidadania" (RODRIGUES, 2003, p.142).

Toschi (2004) defende que o vínculo entre educação e comunicação merece a atenção das instituições, pois afirma que os conteúdos veiculados pela mídia são intrínsecos ao processo educativo e que não se pode ignorar a relevância que a comunicação de massa tem na vida social.

Para além dessas razões, é fato que as cores e as imagens exercem fascínio sobre os sentidos humanos (ALMEIDA, 2006). O autor relaciona o grande consumo da linguagem televisiva à simplicidade, pela facilidade de entendimento no tocante ao seu formato de roteiro e também pela predominância da linguagem oral, que não exige grande esforço do espectador (ALMEIDA, 2006).

Em face de semelhantes características da TV - como estar presente no cotidiano das crianças, possuir poder de atratividade, ter capacidade de informar e entreter, dispor de uma linguagem de fácil 
apreensão -, amplia-se a necessidade de discussão pelo campo educacional desse recurso e de seus produtos.

Identifica-se que a televisão conserva grande potencial para atingir o interesse da criança, podendo auxiliar professores em sua ação educativa e crianças na sua aprendizagem. Logo, é perceptível a utilização da TV como recurso que auxilie o professor na mediação pedagógica para motivar a reflexão e a aprendizagem. Dessa forma, a intenção da pesquisa é aproveitar justamente os elementos da TV para despertar o desejo e provocar a compreensão e o entendimento de uma LE, sendo esses elementos citados por Figueiredo (1995) como fatores inerentes à aprendizagem de outra língua.

\section{Análise dos dados}

Ao analisar a entrevista inicial com as 26 crianças, notamos que nenhuma delas havia frequentado aulas de línguasou mesmo conhecia outro idioma; todas possuíam televisorem casa (entretanto, uma assistia à TV na casa da avó ou de uma amiga (vizinha), pois a antena da sua televisão apresentava defeito); e todas gostavam de assistir à televisão.

Assim, é possível afirmar que as crianças, como as desta instituição, mesmo não tendo acesso a um aprendizado sistematizado de línguas, como, por exemplo, oportunidade de frequentar escolas específicas de línguas, convive com a multiplicidade de línguas que lhe chega por meio do rádio, da televisão e da internet, entre outros. Nesse contexto, as mídias representam, como mostram os dados de nosso estudo, o maior meio de socialização e acesso ao contato com outras línguas das crianças da comunidade investigada.

$\mathrm{O}$ episódio foi assistido em um ambiente tranquilo e desprovido de tensão, propício à aprendizagem (KRASHEN, 1985). As crianças aguardavam a exibição do programa à vontade, brincando e deitando-se no chão. Primeiramente o episódio foi exibido no idioma original, espanhol. Após o reconhecimento imediato dos personagens e 
de suas ações e falas características, as crianças pareciam engajadas na atividade:

[1] Olha o Kiko, olha a Chiquinha, esse aí é o seu Madruga [criança A].

A dona Florinda vai bater nele [criança B].

Olha o Chaves, ele chora assim: bi, bi, bi, bibi... [criança C].

Logo demonstraram estranhamento quanto ao modo como falavam. A proximidade sonora do espanhol com o português pode ter contribuído para que a sensação de "algo errado" tenha demorado alguns minutos. As crianças entreolhavam-se e faziam expressões de interrogação, verbalizavam a situação [2] e forneciam soluções para o que acreditavam ser um problema [3]:

[2] Não estão falando direito [criança D].

O DVD está arranhado [pedindo na sequência para trocá-lo - criança B].

Não estou ouvindo [várias crianças].

Aqui não falam direito, no lá de casa não falam assim [criança F].

[3] Aumente o volume da TV [criança E].

Não, tia. Abaixe o volume, tá muito alto [criança A].

As crianças associaram a falta de compreensão linguística ao fato de os personagens estarem "falando certo" ou "falando errado". Logo, conclui-se que aquilo que corresponde ao desconhecido, o que foge do esperado por elas é considerado um erro, é o estrangeiro se manifestando. Quanto a isso, recorre-se a Almeida Filho (2012), para quem é preciso desestrangeirizar a sensação da outra língua que se apresenta na escola para que o sucesso da aprendizagem seja maior.

Um ambiente colaborativo, tal como o estabelecido nesta pesquisa, é reconfortador (SABOTA, 2008), ao deparar-se com dificuldades, as crianças buscam apoio e solução de problemas no outro, que pode ser um colega ou a professora, como o pedido da criança no excerto 3 anterior. 
O suporte, scaffolding, fornecido pelos colegas e pela professora proporcionou a discussão e a interação entre eles. Em alguns momentos, as próprias crianças começavam a processar a LE e expressavam suas próprias elaborações por meio das colaborações recebidas. Elas começavam a buscar entendimentos e arriscavam na compreensão da nova língua, agarrando-se à semelhança de palavras cognatas. Um exemplo bem significativo ocorreu quando a personagem dona Florinda (mãe do Kiko) diz: “nino”. Uma criança interpretou "ninho" e a outra disse:

[4] Não é ninho, ela é a mãe dele, olhe lá, ela está falando meu filho [criança A].

Nesse ponto, nota-se que o recurso midiático (no caso a televisão) teve um papel preponderante, pois a partir da junção de imagem, animação e som a criança produziu um efeito de sentido apoiada no contexto que auxiliou no entendimento e na recepção, possibilitando imersão na nova experiência, mesmo sendo uma língua desconhecida. A compreensão do vídeo, tal como na compreensão de um texto, requer que as crianças utilizem pistas não verbais além de seu conhecimento prévio sobre o programa para compensar o não conhecimento da LE (NUTTALL, 1996). Assim, primeiramente as crianças reconheceram ações (brigas, afetos, conversas, brincadeiras entre os personagens) e então interpretaram o texto televisivo.

Ao sentirem estranhamento na compreensão do enunciado, algumas crianças atribuíram o som estrangeiro da língua como pertencente ao idioma inglês, como mostra o excerto 5:

[5] Está em inglês [criança H].

O DVD está em inglês, tem que passar para o português [criança D].

Muda, tia, no controle, aperta aí... Muda para português [levantando-se para fazer a alteração no controle - criança $\mathrm{M}]$.

Neste momento, foi possível perceber uma atitude mais assertiva na criança em relação à solução do problema, passando da sugestão (como no excerto 3) à ação (excerto 5). A solicitação de Horizontes de Linguística Aplicada, ano 12, n. 2, 2013 
mudança de idioma sugere ainda que a LE passa a soar como uma alternativa (sugerindo a alteração de idiomas no controle remoto), indicando a aceitação da língua, como mencionado por François (2006), as crianças entram na língua e fazem emergir um significado.

A hegemonia do inglês como LE, citada nos PCN-LE (BRASIL, 1998),faz-se evidente até mesmo entre as crianças participantes da pesquisa.Para lidar com a questão da hegemonia, neste momento a pesquisadora pausou o vídeo e iniciou um breve debate sobre o tema:

[6] Pesquisadora: Por que você acha que está em inglês?

Porque a gente não entende... [criança $\mathrm{A}$ ].

É, a gente não entende, tia [criança G].

Tem que passar para o português. No controle, meu pai faz isso [criança $\mathrm{C}$ ].

Cabe ressaltar que, comumente, as crianças atribuem a todo som ou forma de comunicação que não conseguem compreender como sendo língua inglesa. Isso se dá, conforme Ortiz (2008, p. 32), por ser a língua de que mais ouvem falar, e pelo fato de que "a globalização declina-se especialmente em língua inglesa”. Para o autor, essa situação tem sérias implicações no interior dos campos sociais, especialmente no científico, no qual seria possível observar o aumento crescente do uso do inglês em detrimento das demais línguas. As construções que as crianças elaboravam surtiam um "efeito cascata": seguidamente ao comentário de um, relembravam fatos, associavam ideias, criavam situações com as quias não concordavam e as acrescentavam às falas dos colegas.

Neste momento da pesquisa, insiste-se pela continuidade do programa na língua espanhola, original dos personagens. Num dado momento, os alunos começaram a repetir as palavras que conseguiam compreender ou que reconheciam. Emitiram vários sons estranhos, imitando o idioma sem compreensão, colocaram a língua para fora da boca e reproduziram sons que não tinham significados. Tentaram reproduzir o que estavam ouvindo e deixaram claro que não apresentavam significados para eles: 
[7] Blublublublu ...blublublu...blublu... [criança I].

Professora, eles falam assim: blá, blá, blá, blu, blublu, blablu... [criança J].

Eles falam depressa e tudo enrolado, nintiendonênonênolilo [criança K].

Apesar de não haver resistência à participação na atividade, a tolerância à ambiguidade dessas crianças foi colocada em exercício neste momento, aguçando sua curiosidade e impelindo-as a arriscar-se. Enquanto alguns emitiam "sons sem significado", alguns demonstravam que estavam entendendo parte do léxico do espanhol e se arriscavam na repetição de alguns itens, como pode ser visto nos excertos que seguem:

[8] Tia, a Chiquinha tava falando com uma língua diferente: nino [criança I].

Tia, o Kiko disse: simmami [criança B].

Essa repetição de itens demonstra que as crianças começaram a assimilar a língua espanhola ao tentarem reconhecer palavras, ousando inclusive ao tentarem novos termos, por generalização. Quando uma criança disse "sim, mami", seguidamente, outra criança complementou:

[9]Sim, papi [criança C].

Cabe ressaltar que "sim papi" não foi fala do vídeo, mas uma elaboração da criança, ou seja, construção dela própria por transferência generalizadora (mamãe $\rightarrow$ mami; papai $\rightarrow$ papi). O processo de aprendizagem de uma LE pode se dar de modo natural, ainda que em ambiente formal, como o CMEI. Como percebemos, o processo é dinâmico, e os novos scaffoldings e construções linguísticas podem ser fornecidos por textos, vídeos, professores e também pelas próprias crianças.

Após a sessão de vídeo seguiram-se alguns questionamentos às crianças sobre a experiência vivida. Como nosso interesse investigativo recai sobre a língua, elaboramos algumas perguntas: 
[10] Pesquisadora: Vocês já viram alguém falar da forma como os personagens falaram no programa passado na TV [versão em espanhol]?

Eu já vi uma pessoa falar diferente no computador [criança A].

Pra entender, tem que colocar em português [criança E].

Reprisamos, na sequência, uma pequena parte do vídeo em espanhol. Nesse momento, as crianças mostraram certa resistência em assistir ao vídeo novamente em LE. Entretanto, desviaram o foco da compreensão para o fenômeno "falar uma LE". Como pode ser percebido no excerto 11, o fascínio pelo vídeo, nesse momento, é menor do que o exercido pela língua. No diálogo entre uma criança e a pesquisadora e nas falas seguintes é possível ver a relação que estabelecem: inglês para falas cuja compreensão não é possível e português para o que conseguem compreender:

[11] Eu já vi um homem falar em inglês lá do lado da casa da minha avó [criança N].

Quem é este homem? Ele veio de outro lugar? De outro país? [pesquisadora].

Não, ele não tem dentes e fala tudo enrolado. A gente não entende [criança $\mathrm{O}]$.

$\mathrm{O}$ porco fala inglês [criança $\mathrm{P}$ ].

O cachorro também[criança Q].

Minha irmãzinha mais nova fala inglês [criança R].

Agora, a dicotomia português-inglês recai sobre todos os sons diferentes, externos ao seu sistema linguístico em consolidação. Para algumas crianças, o grunhir do porco, o latido do cachorro, o balbucio da irmãzinha mais nova são emissões em inglês (!).Esse entendimento do que seja falar uma língua estrangeira, compreendido como a produção de sons desconhecidos começa para algumas crianças a se referir à experiência de uma LE associado à música (excerto 12). Ressalte-se que a criança associa o saber cantar a saber o idioma, portanto há uma associação com o uso da língua. 
[12] Meu pai sabe inglês [criança D].

Como? Ele morou em outro país? [pesquisadora].

Não, ele canta música que eu não entendo [criança D].

Meu pai também sabe inglês. Eu sei disso porque ele ouve no som [criança $F$ referindo-se a músicas internacionais].

As crianças começaram a sistematizar diferentes usos e formas de linguagem. O rádio e o aparelho de som não geraram dúvidas quanto à exatidão do conteúdo, o que é veiculado nessas mídias é língua, e a música, quando não compreendida, diferentemente da fala no vídeo, não está certa ou errada, mas pertence a outra língua. Prosseguimos a série de perguntas às crianças questionando sobre qual língua falamos, ao que uma delas respondeu:

[13] Essa língua [apontando para o órgão - criança E].

A criança E mostra-se conhecedora da polissemia da palavra "língua", mas não consegue ainda conceituar língua, compreensivelmente atribuída a um conceito abstrato (FRANÇOIS, 2006). Iniciamos, então, um momento de intervenção mediadora e informamos que existem outros idiomas, outros meios de se comunicar usando palavras. Uma menina questiona se essa linguagem será usada no céu, não tendo consciência de outros países.

[14] Lá no céu, todo mundo fala assim?[criança S].

Começamos a explorar o conceito de país com os participantes do estudo, buscando fornecer um scaffolding para a construção de mais um conceito linguístico (científico e, portanto, abstrato). Algumas crianças começaram a construir, com dificuldade, tal conceito com o apoio de colegas, mediado pela pesquisadora (scaffolding duplo).

[15]Alguém sabe o que é um país? [pesquisadora].

Eu sei. É o Brasil [criança F].

Então o que é o Brasil? [pesquisadora].

Um jogo [criança F, referindo-se ao futebol]. 
A partir desse ponto foram proporcionadas situações para a desconstrução de alguns conceitos espontâneos e oferecidas situações para que fossem construídos outros conceitos, mais exatos, porém sempre em uma perspectiva dialógica. Para desconstruir a ideia de que animais, o banguela e os bebês falam inglês, por exemplo, foi apresentado o vídeo com emissão de imagens e sons sobre animais e bebês seguido de questionamento mediador:

[16] Os porcos conversam? Os cachorros conversam? Dois bebês que estão balbuciando estão conversando?Estão se entendendo?[pesquisadora].

Porco conversa só com porco e cachorro não conversa com porco [criança R].

O momento em que uma criança concluiu que o bebê está aprendendo a falar foi significativo, ao passo que outra criança intuiu que os animais não vão aprender a falar. A declaração "porco conversa só com porco" foi importante para percebermos a construção do conceito, por meio do acesso que tivemos à lógica do pensamento infantil, em pleno desenvolvimento. Elas demonstraram ter começado a entender que a língua é um código compartilhado socialmente e que contém aspectos característicos do grupo a que pertencem.Embora a analogia com os ruídos de animais não corresponda a esse conceito, no imaginário infantil, por intermédio do conhecimento prévio construído como espectador de desenhos infantis, o grunhir e o latir também representam um tipo de fala. Com o tempo esse conceito pode evoluir e amadurecer para a compreensão de que a fala é uma produção cultural humana.

\section{Considerações finais}

Nesta pesquisa com crianças de 4 anos foi desenvolvida uma sequência de atividades com o intuito de perceber a reação delas quanto à língua. Pretendia-se que as crianças pudessem, pelo contato, se relacionar com essa língua e construir alguma compreensão do programa assistido em outra língua diferente da sua. 
Nosso estudo, tal como o de Rocha (2007), apresentou reflexões sobre a importância da mediação nas interações para a construção (e a ampliação) dos conceitos de língua, descrevendo exemplos de uso situado da linguagem para o favorecimento da construção da identidade linguística de crianças pequenas. Atividades foram propostas para mediar o avanço da construção do conceito de LM, nossa língua, e de LE, a língua do outro.

A pesquisa aponta para outra questão que carece ser estudada com mais frequência: o aproveitamento do potencial da televisão para participar como recurso tecnológico na educação da criança pequena, principalmente por comportar uma gama de conhecimentos culturais, sociais e de gêneros discursivos (TOSCHI, 2004; RODRIGUES, 2003).

Infere-se, com base neste estudo, que a construção do conhecimento da e sobre a língua, neste caso sobre a LE (espanhol), iniciada pelas crianças é viável quando desenvolvida de modo mediado e contextualizado. Este estudo permite-nos afirmar que é possível introduzir a discussão sobre a consciência de uma LE muito cedo na vida do ser humano e despertar o desejo pela aprendizagem, fator essencial para a eficácia da empreita, como aponta Figueiredo (1995). Ao mesmo tempo, é importante investir nos benefícios extralinguísticos que o contato com uma LE pode proporcionar, como o conhecimento de culturas distintas e a consciência do outro, como mostra o depoimento de uma criança durante esta pesquisa: Eu quero falar a língua deles!

Essa discussão precoce sobre o assunto pode despertar nas crianças pequenas o interesse para a aprendizagem, como vimos em alguns excertos, e contribuir para sua formação educacional.

Nosso intento com este estudo de perceber como as crianças desenvolvem a consciência linguística pode ser considerado uma importante contribuição para uma área ainda carente de estudos, como apontado por Fernandez e Rinaldi (2009): reflexões e investigações sobre os benefícios da introdução de LE na educação infantil, gerando até mesmo implicações para remodelações no currículo dos cursos de Letras quanto à formação de professores de línguas para crianças pequenas. 


\section{Referências}

ALMEIDA FILHO, José C. P. de. Quatro estações no ensino de línguas. Campinas: Pontes, 2012.

ALMEIDA, Maria Elizabeth. A TV e a educação: curso de especialização tecnologias em educação: pós-graduação lato sensu. Guia do curso 2006/2007. Rio de Janeiro: Coordenação Central de Educação a Distância; Brasília: MEC, 2006.

BRAGA, Denise. B. Ambientes digitais: reflexões teóricas e práticas. São Paulo: Cortez, 2013.

BRASIL.Ministério da Educação e Cultura.Parâmetros Curriculares Nacionais - Língua Estrangeira. Brasília:Secretaria de Educação Fundamental, 1998.

.Ministério da Educação e Cultura.Diretrizes Curriculares Nacionais para a Educação Infantil.Brasília: Secretaria de Educação Básica, 2010.

.Congresso Nacional. Lei de Diretrizes e Bases da Educação Nacional. Lei n. 9.394, 20 de dezembro de 1996.Publicado no Diário Oficial da União de 17 de dezembro de 1996.

FERNANDEZ, Gretel; RINALDI, Simone. Formação de professores de espanhol para crianças no Brasil: alguns caminhos possíveis. Trabalhos em Linguística Aplicada,Campinas, v. 48, n. 2, p. 353-365, jul./dez. 2009.

FIGUEIREDO, Francisco J. Q. de. A aquisição e aprendizagem de segunda língua. Signótica,v.7, p. 39-57, jan./dez. 1995.

FRANÇOIS, Frédéric. O que nos indica a "linguagem da criança": algumas considerações sobre a "linguagem". In: DEL RÉ, Alessandra. Aquisição da linguagem. São Paulo: Contexto, 2006. 
GUARESCHI, Pedrinho. A.; BIZ, Osvaldo. Mídia, educação $e$ cidadania: tudo o que você deve saber sobre mídia. Petrópolis: Vozes, 2005.

KRASHEN, Stephen. The input hypothesis: issues and implications. Harlow: Longman, 1985.

MINAYO, Maria C. de S. O conceito de representações sociais dentro da sociologia clássica. In: GUARESCHI, Pedrinho; JOYCHELOVITCH, Sandra (Org.). Textos em representações sociais. Petrópolis: Vozes, 1995.

LUDKE, Menga; ANDRÉ, Marli. Pesquisa em educação: abordagens qualitativas. São Paulo: EPU, 2013.

MELO, Heloísa A. B. de. L1: madrinha ou madrasta?: o papel da L1 na aquisição da L2. Signótica, v. 16, n. 2, p. 213-242, jul./dez. 2004.

NUTTALL, Christine. Teaching reading skills in a foreign language.Hong Kong: Macmillan ELT, 1996.

OLIVEIRA, Eliane. C. de. Navegar é preciso!: o uso de recursos tecnológicos para um ensino-aprendizagem significativo de línguas estrangeiras. In: PEREIRA, Ariovaldo L.; GOTTHEIM, Liliana. Materiais didáticos para o ensino de língua estrangeira: processos de criação e contextos de uso. Campinas: Mercado de Letras, 2013. p. 185-214.

ORTIZ, Renato. A diversidade dos sotaques: o inglês e as ciências sociais. São Paulo: Brasiliense, 2008. Disponível em:<http://www.scielo.br.> Acesso em: 20 fev. 2013.

PANIAGUA, Gema; PALACIOS, Jesús. Educação Infantil: resposta educativa à diversidade.Artmed: Porto Alegre, 2007.

ROCHA, Cláudia H. O ensino de línguas para crianças no contexto educacional brasileiro: breves reflexões e possíveis provisões. 
DELTA, v. 23, n. 2, 2007. Disponível em:

<file:///C:/Users/Cláudia/Downloads/ClaudiaRocha-

ensinode2013linguasparacriançasa05v23n2(1).pdf >. Acesso em:

23/09/2014.

RODRIGUES, Maria Alexandra Militão. TV/vídeo na Educação Infantil. Curso de Extensão: TV na Escola e os Desafios de Hoje. Brasília: Editora Universidade de Brasília, SEED/MEC/UniRede, 2003.

SABOTA, Barbra R. S. Estágio supervisionado de LE: um estudo de caso sobre a formação universitária de professores de inglês na UFG. 2008. 231 f. Tese (Doutorado em Letras e Linguística) - Faculdade de Letras, Universidade Federal de Goiás, Goiânia, 2008.

SILVA, Marco. Sala de aula interativa. 4. ed. Rio de Janeiro: Quartet, 2007.

TOSCHI, Mirza S. Educação para as mídias: conceito, relação com a educação e experiências. Todos os contos. Goiânia: Ayvu-Etã, 2004.

VILLAMIL, Olga. S.; GUERRERO, Maria C. M.. Peer Revision in the L2 classroom: social-cognitive activities, mediating strategies, and aspects of social behavior. Journal of Second Language Writing, v. 5, n. 1, p. 51-75, 1996.

VYGOTSKY, Lev S. Pensamento e linguagem. 3.ed. São Paulo: Martins Fontes, 1991.

WOOD, David; BRUNER, Jerome S.; ROSS, Gail. The role of tutoring in problem solving. Journal of Child Psychology and Psychiatry and Allied Disciplines, v. 17, p. 89-100, 1976.

Submetido em: 18/10/2013

Aceito em: 29/09/2014

Title: Does the pig speak English?! The construction of the perception and concept of language by four-year-old children

104 Horizontes de Linguística Aplicada, ano 12, n. 2, 2013 